\title{
Properties of filamentary nanocrystals of cadmium sulfide synthesized by vacuum evaporation and condensation
}

\author{
(C) Alexey P. Belyaev, ${ }^{1+}$ Vladimir P. Rubetz, ${ }^{2}$ and Vladimir V. Antipov ${ }^{2}$ \\ ${ }^{1}$ Department of Phisical and Colloidal Chemistry. St. Petersburg State Chemical-Pharmaceutical \\ University. Professor Popov St., 14. St. Petersburg, 197376. Russia. \\ Phone: +7 (812) 499-3900, add.41-40.E-mail: Alexei.Belyaev@pharminnotech.com \\ 2 Department of Analytical Chemistry. St Petersburg State Institute of Technology (Technical University). \\ Moscovsky Ave., 26. Saint-Petersburg, 190013. Russia. \\ Phone:+7 (812) 494-93-71.E-mail:vladimir@mail.ru
}

\begin{abstract}
*Supervising author; ${ }^{+}$Corresponding author Keywords: filamentary nanocrystals; synthesis form vaporous phase; structural studies; electron diffraction.
\end{abstract}

\begin{abstract}
In recent decades, 1D structures, such as Nano whiskers, nanowires, Nano rods, etc., have attracted considerable interest of researcher due to their highly promising application in electronics, photonics, energy conversion and storage systems, medicine and pharmacology, and in modeling interaction with biomolecules and living calls. A prominent place among nanostructures is occupied by $1 \mathrm{D}$ nanostructures grown perpendicular to the substrate surface. These nanostructures are called Nano whiskers. Below reported about physicochemical studies of the ensemble of filamentary nanocrystals of cadmium sulfide synthesized by vacuum evaporation and condensation. It is presented the results of technological experiments, the results of electronic microscopy and the results of electron diffraction studies. It is shown that by means of vacuum evaporation and condensation it is possible to synthesize filamentary nanocrystals of diameter from $10 \mathrm{~nm}$ to few $\mu \mathrm{m}$ and of the length of few $\mathrm{mm}$. It is revealed technological conditions necessary for the synthesis of filamentary nanocrystals. It is determined relation between growth rate of filamentary nanocrystals and their linear characteristics. It is shown that mechanism of growth of nanocrystals synthesized by used method is in full accordance with model views of classical mechanism vapor-liquid-crystal of Givargizov-Chernov.

For revealing of crystalline perfection of filamentary nanocrystals it is used electron diffraction method, at so doing for increasing of the level of analytical signal it is used superposition of diffraction patterns from ensemble of filamentary nanocrystals. The method proposed permitted establish high degree of perfection of filamentary nanocrystals synthesized by vacuum evaporation and condensation.
\end{abstract}

\section{References}

[1] A.P. Belyaev, V.P. Rubets, and S.A. Belyaeva. Crystallization of cadmium telluride on single crystal substrates cooled with liquid nitrogen. Butlerov Communications. 2015. Vol.41. No.2. P.155-159. DOI: 10.37952/ROI-jbc-01/15-41-2-155

[2] I.Yu. Shirokova, V.I. Kuchuk, A.P. Belyaev, N.N. Shevchenko, and E.V. Golikova. Aggregate stability of disperse systems. Part 1. Investigation of surface electrical properties and coagulation kinetic of monodisperse polystyrene latexe particles with surface carboxyl groups. Butlerov Communications. 2014. Vol.37. No.2. 3.2938. ROI: jbc-02/14-37-2-29

[3] I.Yu. Shirokova, M.S. Tereshchenko, I.D. Shpilina, A.P. Belyaev, V.I. Kuchuk, N.N. Shevchenko, and E.V. Golikova. Investigation of surface electrical properties and agregate stability of monodisperse polystyrene latexe particles with aminated surface. Butlerov Communications. 2014. Vol.39. No.9. P.98106. ROI: jbc-02/14-39-9-98

[4] E.Yu. Rodionova, I.B. Dmitrieva, and A.S. Chukhno. Influence of the dispersion medium composition on the stability and electrokinetic properties of bilirubin. Butlerov Communications. 2014. Vol.37. No.1. C.55-61. ROI: jbc-02/14-37-1-55

[5] A.P. Belyaev, V.P. Rubets, V.V. Antipov, E.O. Eremina. Nucleation of CdTe Islands during Synthesis from the Vapor Phase on a Cooled Substrate. Semiconductors. 2011. Vol.45, No.10. P.1297-1300. 
[6] A.P. Belyaev, V.P. Rubets, I.P. Kalinkin. Optical Absorption Edge and Modification Due the Decomposition on Cadmium Telluride and Cadmium Sulfide Solid Solution Films. Semiconductors. 1997. Vol.31. No.5. P.540-542.

[7] A.P. Belyaev, V.P. Rubets, I.P. Kalinkin. Conductivity Stimulated by Temperature Oscillations in Dissociated Cadmium Telluride and Cadmium Sulfide Solid Solutions. Semiconductors. 1997. Vol.31. No.8. P.823-825. (russian)

[8] A.P. Belyaev, V.P. Rubets, V.V. Antipov, N.S. Bordei. On the mechanism of initial stage of formation of nanostructures in conditions of ultralow temperatures. "Nanosystems: Physics, Chemistry, Mathematics". 2012. Vol.3. No.5. P.103-110. (russian)

[9] A.P. Belyaev, V.P. Rubets, V.V. Antipov, A.O. Ribnikov, and S.A. Belyaeva. Crystallization of paracetamol of rhombic form. Butlerov Communications. 2014. Vol.37. No.3. P.113-119. ROI: jbc$02 / 14-37-3-113$

[10] A.P. Belyaev, V.P. Rubets, V.V. Antipov, N.S. Bordei. Phase Transformations during the Growth of Paracetamol Crystals from the Vapor Phase. Technical Physics. 2014. Vol.84. No.7. P.1101-1103.

[11] R.S. Wagner, W.C. Ellis. Vapor-Liquw-Solid Mechanism of Single Crystal Growth. Appl. Phys. Lett. 1964. Vol.4. No.5. P.89.

[12] V.G. Dubrovskiia, G.E. Cirlina, V.M. Ustinova. Semiconductor Nanowhiskers: Synthesis, Properties, and Applications. Semiconductors. 2009. Vol.43. No.12. P.1539-1586.

[13] Y. Zong, Z. Yue, P. Martins, J. Zhuang, Y. Du, S. Lanceros-Mendez, M. Higgins. Magnetoelectric coupling in nanoscale 0-1 connectivity. Nanoscale. 2018. Vol.10. Iss.36. P.17370-17377.

[14] X. Liu, Y. Li, J. Sun, Y. Zhang, X. Yang. Preparation of TiC-SiC composite coatings on graphite flakes and their effects on hydrophilicity and dispersivity. Surface and Coatings Technology. 2019. Vol.357. P.706-715.

[15] B. Yin, G. Li , D. Wang, L. Wang, J. Wang, H. Jia, L. Ding, D. Sun. Enhanced mechanical properties of styrene-butadiene rubber with low content of bacterial cellulose nanowhiskers. Advances in Polymer Technology. 2018. Iss.5. P.1323-1334.

[16] J.M. Salva, D.D. Gutierrez, L.A. Ching, P.M. Ucab, H. Cascon, N.P. Tan. Solution blow spinning (SBS)-assisted synthesis of well-defined carboxymethyl cellulose (CMC) nanowhiskers Nanotechnology. 2018. Vol.29. Iss.50. No.5 0LT01

[17] A. Espadín, L.T. De Dios, E. Ruvalcaba, J. Valadez-García, C. Velasquillo, I. Bustos-Jaimes, H. Vázquez-Torres, M. Gimeno, K. Shira. Production and characterization of a nanocomposite of highly crystalline nanowhiskers from biologically extracted chitin in enzymatic poly( $\varepsilon$-caprolactone). Carbohydrate Polymers. 2018. Vol.181. P.684-692

[18] J. Liao, P. Zou, S. Su, A. Nairan, Y. Wang, D. Wu, C.-P. Wong, F. Kang, C. Yang. Hierarchical nickel nanowire $\mathrm{NiCo}_{2} \mathrm{~S}_{4}$ nanowhisker composite arrays with a test-tube-brush-like structure for highperformance supercapacitors. Journal of Materials Chemistry A. 2018. Vol.6. Iss.31. P.15284-15293.

[19] A. Hebeish, S. Farag, S. Sharaf, T.I. Shaheen. High performance fabrics via innovative reinforcement route using cellulose nanoparticles. Journal of the Textile. 2018. Vol.109. Iss.2. P.186-194.

[20] V.V. Simakov, I.V. Sinev, A.V. Smirnov, A.I. Grebennikov. Effect of Temperature on the Growth Rate of Tin Dioxide Whiskers Formed by Physical Vapor Deposition. Technical Physics. 2016. Vol.86. No.4. P.574-578.

[21] A.P. Belyaev, V.P. Rebets, V.V. Antipov, S.A. Belyaeva, and A.V. Grishina.Vacuum condensation of filiform nanocrystals of cadmium sulfide. Butlerov Communications. 2016. Vol.46. No.4. P.61-64. DOI: 10.37952/ROI-jbc-01/16-46-4-61

[22] E.I. Givargizov. Growth of filiform and lamellar crystals from vapour. Moscow: Nauka. 1977. 304p. (russian) 